\title{
Electrode Kinetics of Organodisulfide Cathodes for Storage Batteries
}

\author{
Meilin Liu, ${ }^{*, 1}$ Steven J. Visco, ${ }^{*}$ and Lutgard C. De Jonghe \\ Department of Materials Science and Mineral Engineering, University of California, and Materials and Chemical \\ Sciences Division, Lawrence Berkeley Laboratory, Berkeley, California 94720
}

\begin{abstract}
The electrode kinetics of a diverse group of organodisulfide cathode materials have been systematically investigated. The electrochemical behavior of these redox couples was studied as a function of the organic moiety $(R)$ in the organodisulfide compounds (RSSR). These studies were performed with a variety of working electrodes, including platinum, glassy carbon, graphite, stainless steel, aluminum, and copper. The possible reaction pathways and mechanisms have been hypothetically postulated, theoretically analyzed, and experimentally verified. Observations showed that while electron transfer rate constants varied with organic moiety, the mechanistic details of the redox path were invariant with the $R$ groups of the organodisulfides studied. The reaction mechanism, as determined from experimental observations, can be expressed as
\end{abstract}

$$
\begin{gathered}
2\left[\mathrm{RS}^{-} \rightarrow \mathrm{RS}^{*}+e^{-}\right] \\
\mathrm{RS}^{*}+\mathrm{RS}^{*} \rightleftarrows \mathrm{RSSR}
\end{gathered}
$$

for the oxidation of thiolate anions (RS ${ }^{-}$) to the corresponding organodisulfides. The first step in the redox mechanism, charge transfer, is rate determining, while the second step, chemical reaction, is at equilibrium. The observed transfer coefficients are quite asymmetric and vary as a function of the R group in RSSR and the electrode materials. The standard rate constants are also affected by the nature of the organic moiety, $R$, and are in the range of $10^{-8}-10^{-6}$ from ambient to $100^{\circ} \mathrm{C}$. Further, and in particular, electrode kinetics have been enhanced by the addition of several electrocatalysts.

Advanced high temperature secondary batteries incorporating solid electrolyte separators offer many advantages over conventional cells, including high specific energy and power density, as well as excellent charge retention on storage due to negligible self discharge. Still, the impressive performance of these cells is offset somewhat by the technical difficulties of operating batteries at high temperatures. Accordingly, various efforts have been made to introduce alternative high specific power/energy batteries operating at reduced temperatures (1-4), including the sodium $/ \beta^{\prime \prime}$-alumina/RSSR cell (5). However, since mass transport and electrode kinetics are thermally activated, a thorough understanding of these processes is necessary for successful operation of lower temperature systems.

It is well known that the efficiency and power of an electrochemical energy conversion system increases with increasing the rate of electrode kinetics and mass transport, and with decreasing internal resistance. Accordingly, for batteries such as the alkali metal/organodisulfide cells (5), the critical limitations on charge-transfer rates are essentially determined by the nature of the positive electrode. Although the electrode reactions of organodisulfide/thiolate redox couples have been reported previously to be kinetically kindered $(6,7)$, particularly at ambient temperatures, their reversibility can be substantially enhanced by introducing appropriate electrocatalysts. The identification of effective catalysts, however, can only emerge from a detailed understanding of the kinetic mechanisms that control the overall process.

The investigation of electron transfer reaction kinetics generally involves the determination of reaction route, mechanism, and kinetic parameters (8). The reaction route refers to a successive sequence of elementary reactions which constitute the overall, stoichiometric electrode reaction, while the mechanism specifies the rate-controlling nature of the constituent steps and their coupling (9). The basic kinetic parameters characterizing an electrode reaction include: $(i)$ the reaction order, $(i i)$ the standard rate constant or exchange current density, (iii) the symmetry factor for the rate determining step (rds) or apparent transfer coefficients, (iv) the stoichiometric coefficients, and $(v)$ the activation energy. The above parameters can be determined from the dependence of reaction rate (i.e, current) on various observables, including overpotential across the

* Electrochemical Society Active Member.

${ }^{1}$ Present address: Ceramatec, Incorporated, Salt Lake City, Utah interface, composition of the electrolytic solution adjacent to the electrode, the nature of the electrode surface, and temperature.

The purpose of this study is to elucidate the kinetic behavior of a diverse group of organodisulfide/thiolate redox couples, and to provide a basis for identifying effective electrocatalysts for activation of these redox reactions. The effect of temperature on electrode kinetics as well as on transport properties will be addressed in a subsequent communication (10).

\section{Experimental}

Organosulfur compounds (tetramethylthiuram disulfide (TMTD), tetraethylthiuram disulfide (TETD), phenyl disulfide (PDS), di-fluorophenyl disulfide (FPDS), sodium diethyl dithiocarbamate (NaDEDC), sodium dimethyl dithiocarbamate (NaDMDC)], supporting electrolyte [tetraethylammonium perchlorate (TEAP)], reference electrode filling electrolyte [tetramethylammonium chloride (TMAC)], and dimethylsulfoxide (DMSO) were prepared and stored as described in a previous publication (6). Dimethyldisulfide (DMDS) was obtained from Aldrich ${ }^{1}$ and distilled under vacuum over molecular sieves. Transition metal phthalocyanines (MPc), were obtained from Pfaltz \& Bauer $^{2}$ and stored in an argon atmosphere dry box.

$\mathrm{An} \mathrm{Ag} / \mathrm{AgCl}$ reference electrode ${ }^{3}$ was connected to the working electrode compartment with a Luggin capillary salt bridge containing a $0.1 M$ TEAP solution. The reference electrode compartment contained a $0.1 M$ TMAC aqueous solution saturated with $\mathrm{AgCl}$.

Three-electrode electroanalytical cells with platinum auxiliary electrodes were used throughout the experiments. Planar disks (diam $=0.8 \mathrm{~cm})$ of platinum, glassy carbon, graphite, stainless steel, aluminum, and copper metal were used as the working electrodes. Before each experiment, the working electrodes were polished to a mirror finish with diamond paste $(1 \mu \mathrm{m})$ and rinsed with acetone.

Unless otherwise stated, electrolyte solutions consisted of $0.1 M$ TEAP in DMSO and electrode potentials were measured vs. a Ag/AgCl reference electrode. The electrolyte solutions were purged with dry argon for about $10 \mathrm{~min}$ prior to experimentation and continuously purged at slower rates during each measurement.

\footnotetext{
${ }^{1}$ Aldrich Chemical Company, Incorporated, Milwaukee, Wiscon$\sin 53233$.

${ }^{2}$ Pfaltz \& Bauer, Incorporated, Waterburg, Connecticut 06708.

${ }^{3}$ Astra Scientific.
} 
In rotating disk voltammetry (11-13), linear or triangular potential functions, generated by a PAR 173 potentiostat/ galvanostat ${ }^{4}$ in conjunction with a PAR 175 Universal Programmer, ${ }^{4}$ were applied to a disk electrode immersed in the electrolyte solution $\left(150 \mathrm{~cm}^{3}\right)$. The rotation speed of the disk electrode was modulated with an ASR Electrode Rotator ${ }^{5}$ and Speed Controller. ${ }^{5}$ The corresponding current response was either recorded with a $4120 \mathrm{~T}$ Bascom-Turner digital recorder ${ }^{6}$ or acquired with an IBM-PC/AT computer through a DT2801A data translation board ${ }^{7}$ using ASYSTANT $^{8}$ software. The potential sweep rates ranged from 1 to $10 \mathrm{mV} / \mathrm{s}$.

Solution viscosities were measured using a series of Cannon-Fenske Routine Viscometers immersed in an isothermal water bath. The measurement involved determination of the time required for a given volume of the solution to fall through a vertical capillary tube of a given length under the influence of gravity. The apparatus constant of each viscometer was determined through calibration with distilled water.

In linear and Tafel polarization measurements the potential was stepped by a PAR 173 potentiostat/galvanostat and the corresponding currents at each potential were recorded using a Bascom-Turner recorder. ${ }^{6}$ Complications due to mass transfer were eliminated by either stirring the electrolyte solution with a magnetic bar when a stationary electrode was used, or by measuring the current at a RDE at high rotation speed (about $3000 \mathrm{rpm}$ ).

Sodium/ $\beta^{\prime \prime}$-alumina/RSSR cells were galvanostatically controlled by an IBM-PC/AT computer through a DT2801A data translation board ${ }^{7}$ and a PAR 173 potentiostat/galvanostat ${ }^{4}$ using a program written in ASYST, ${ }^{8}$ (25) while the corresponding cell voltages were simultaneously acquired by the computer.

${ }^{4}$ Princeton Applied Research, Hayward, California 94545

${ }_{5}^{5}$ Pine Instrument Company, Grove City, Pennsylvania 16127.

${ }^{6}$ Bascom-Turner, Incorporated, Norwood, Massachusetts 02062

7 Data Translation, Incorporated, Marlborough, Masasachusetts 01752-1192.

${ }^{8}$ Macmillan Software Company.

\section{Kinetic Equations (14-18)}

It was determined previously that the overall, stoichiometric reaction for organodisulfide/thiolate redox couples can be described as $(6)$

$$
\mathrm{RSSR}+2 e^{-} \rightleftarrows 2 \mathrm{RS}^{-}
$$

Under the assumption that complications due to electrode adsorption are negligible, the relationship between current, $i$, and overpotential at the electrode surface, $\eta$, can be described by $(14,16)$

$$
\begin{aligned}
i=i_{0}\left\{\left(C_{\mathrm{RS}^{-}, \mathrm{s}} / C_{\mathrm{RS}^{-}, \mathrm{b}}\right)^{\gamma \mathrm{RS}^{-}} \exp \left(\alpha_{\mathrm{a}} \mathbf{F} \eta / R T\right)\right. & \\
& \left.-\left(C_{\mathrm{RSSR}, \mathrm{s}} / C_{\mathrm{RSSR}, \mathrm{b}}\right)^{\gamma_{\mathrm{RSSR}}} \exp \left(-\alpha_{\mathrm{c}} \mathbf{F} \eta / R T\right)\right\}
\end{aligned}
$$

where $i_{\mathrm{o}}$ is the exchange current, $\gamma_{\mathrm{RS}}$ - and $\gamma_{\mathrm{RSSR}}$ are the anodic and cathodic reaction orders for species $\mathrm{RS}^{-}$and RSSR, and $C_{i, s}$ and $C_{i, b}$ are the concentrations of species $i$ at the electrode surface and in the bulk solution, respectively. The anodic and cathodic transfer coefficients, $\alpha_{\mathrm{a}}$ and $\alpha_{c}$, can be expressed as (16)

$$
\begin{gathered}
\alpha_{\mathrm{a}}=\gamma \rightarrow \nu+r(1-\beta) \\
\alpha_{\mathrm{c}}=\gamma^{\leftarrow} / \nu+r \beta
\end{gathered}
$$

where $\gamma \rightarrow$ is the number of electrons transferred in the steps preceding the rds, $\gamma^{-}$is the number of electrons transferred in the steps after the rds, $r$ is the number of electrons transferred in the rds, $\nu$ is the stoichiometric coefficient, and $\beta$ is the symmetry factor of the rds.

The exchange current can, in general, be expressed as (15)

$$
i_{0}=(n / v) \mathbf{F} A k^{0}\left(C_{\mathrm{RS}^{-}}\right)^{\mu}\left(C_{\mathrm{RSSR}}\right)^{\lambda}
$$

\begin{tabular}{|c|c|c|c|c|}
\hline & Reaction route & & rds & Mechanism no. \\
\hline \multirow[t]{2}{*}{ 1. EC route } & $2\left\{\mathrm{RS}^{-} \underset{k_{\mathrm{cl}}}{\stackrel{k_{\mathrm{al}}}{\rightleftarrows}} \mathrm{RS}+e^{-}\right\}$ & $(1-1)$ & $1^{\mathrm{st}}$ & 1 \\
\hline & $2 \mathrm{RS} \underset{k_{\mathrm{b}}}{\stackrel{k_{\mathrm{f}}}{\rightleftharpoons}} \mathrm{RSSR}$ & $(1-2)$ & $2^{\text {nd }}$ & 2 \\
\hline \multirow[t]{3}{*}{ 2. ECE route } & $\mathrm{RS}^{-} \underset{k_{\mathrm{cl}}}{\stackrel{k_{\mathrm{al}}}{\rightleftarrows}} \mathrm{RS}^{\cdot}+e^{-}$ & $(2-1)$ & $1^{\text {st }}$ & 3 \\
\hline & $\mathrm{RS}^{-}+\mathrm{RS}^{-} \underset{k_{\mathrm{b}}}{\stackrel{k_{\mathrm{f}}}{\rightleftarrows}} \mathrm{RSSR}^{-}$ & $(2-2)$ & $2^{\text {nd }}$ & 4 \\
\hline & $\mathrm{RSSR}^{-} \underset{k_{\mathrm{c} 3}}{\stackrel{k_{\mathrm{a3}}}{\rightleftharpoons}} \mathrm{RSSR}+e^{-}$ & $(2-3)$ & $3^{\text {rd }}$ & 5 \\
\hline \multirow[t]{3}{*}{ 3. CEE route } & $2 \mathrm{RS}^{-} \underset{k_{\mathrm{b}}}{\stackrel{k_{\mathrm{f}}}{\rightleftharpoons}}-\mathrm{RSSR}^{-}$ & $(3-1)$ & $1^{\text {st }}$ & 6 \\
\hline & $\mathrm{RSSR}^{-} \underset{k_{\mathrm{c} 2}}{\stackrel{k_{\mathrm{a} 2}}{\rightleftharpoons}} \mathrm{RSSR}^{-}+e^{-}$ & $(3-2)$ & $2^{\text {nd }}$ & 7 \\
\hline & $\mathrm{RSSR}^{-} \underset{k_{\mathrm{c} 3}}{\stackrel{k_{\mathrm{a} 3}}{=}} \mathrm{RSSR}+e^{-}$ & $(3-3)$ & $3^{\text {sd }}$ & Identical to no. 5 \\
\hline \multirow[t]{3}{*}{ 4. EEC route } & $\mathrm{RS}^{-} \underset{k_{\mathrm{c} 1}}{\stackrel{k_{\mathrm{al}}}{\rightleftarrows}} \mathrm{RS}^{-}+e^{-}$ & $(4-1)$ & $1^{\text {st }}$ & Identical to no. 3 \\
\hline & $\mathrm{RS} \cdot \underset{k_{\mathrm{c} 2}}{\stackrel{k_{\mathrm{a} 2}}{\longrightarrow}} \mathrm{RS}^{+}+e^{-}$ & $(4-2)$ & $2^{\text {nd }}$ & 8 \\
\hline & $\mathrm{RS}^{+}+\mathrm{RS}^{-} \underset{k_{\mathrm{b}}}{\stackrel{k_{\mathrm{f}}}{\rightleftarrows}} \mathrm{RSSR}$ & $(4-3)$ & $3^{\text {rd }}$ & 9 \\
\hline
\end{tabular}

where $n$ is the total number of electrons involved in the overall reaction, $k^{\circ}$ is the standard rate constant, and the exponents $\mu$ and $\lambda$ are constant dependent on the reaction mechanism.

Table I. Possible reaction pathways and the corresponding mechanisms for organodisulfide/thiolate redox couples 
Table II. Kinetic equations and the corresponding reaction orders, transfer coefficients, and stoichiometric coefficients for nine possible reaction mechanisms listed in Table ।

\begin{tabular}{|c|c|c|c|c|c|c|}
\hline \multirow{2}{*}{$\begin{array}{l}\text { Mechanism } \\
\text { no. }\end{array}$} & \multirow{2}{*}{ 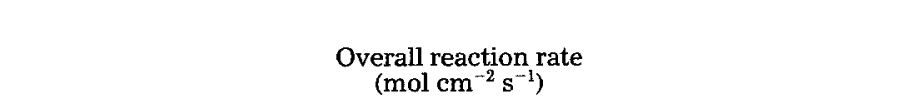 } & \multicolumn{2}{|c|}{$\begin{array}{c}\text { Reaction } \\
\text { order }\end{array}$} & \multicolumn{2}{|c|}{$\begin{array}{c}\text { Transfer } \\
\text { coefficiènt }\end{array}$} & \multirow{2}{*}{$\begin{array}{c}\begin{array}{c}\text { Stoichiometric } \\
\text { coefficient }\end{array} \\
v\end{array}$} \\
\hline & & $\gamma_{\mathrm{RS}^{-}}$ & $\gamma_{\text {RSSR }}$ & $\alpha_{a}$ & $\alpha_{c}$ & \\
\hline 1 & $r_{1}=k_{\mathrm{a} 1}\left(C_{\mathrm{RS}^{-}}\right) \exp \left[\frac{\left(1-\beta_{1}\right) \mathbf{F E}}{R T}\right]-k_{\mathrm{c} 1}\left(\frac{k_{\mathrm{b}}}{k_{\mathrm{f}}}\right)^{1 / 2}\left(C_{\mathrm{RSSR}}\right)^{1 / 2} \exp \left[-\frac{\beta_{1} \mathbf{F E}}{R T}\right]$ & 1 & $\frac{1}{2}$ & $1-\beta_{1}$ & $\boldsymbol{\beta}_{1}$ & 2 \\
\hline 2 & $r_{2}=k_{\mathrm{f}} \frac{k_{\mathrm{a} 1}}{k_{\mathrm{c}^{2}}{ }^{2}}\left(C_{\mathrm{RS}^{-}}\right)^{2} \exp \left[\frac{2 \mathbf{F} E}{R T}\right]-k_{\mathrm{b}} C_{\mathrm{RSSR}}$ & 2 & 1 & 2 & 0 & 1 \\
\hline 3 & $r_{1}=k_{\mathrm{al}}\left(C_{\mathrm{RS}^{-}}\right) \exp \left[\frac{\left(1-\beta_{1}\right) \mathbf{F E}}{R T}\right]-k_{\mathrm{c} 1} \frac{k_{\mathrm{b}} k_{\mathrm{c} 3}}{k_{\mathrm{f}} k_{\mathrm{a} 3}}\left(\frac{C_{\mathrm{RSSR}}}{C_{\mathrm{RS}^{-}}}\right) \exp \left[-\frac{\left(1+\beta_{1}\right) \mathbf{F} E}{R T}\right]$ & 1 & 1 & $1-\beta_{1}$ & $1+\beta_{1}$ & 1 \\
\hline 4 & $r_{2}=k_{\mathrm{f}} \frac{k_{\mathrm{al}}}{k_{\mathrm{c} 1}}\left(C_{\mathrm{RS}}\right)^{2} \exp \left[\frac{\mathbf{F E}}{R T}\right]-k_{\mathrm{b}} \frac{k_{\mathrm{c} 3}}{k_{\mathrm{a} 3}}\left(C_{\mathrm{RSSR}}\right) \exp \left[-\frac{\mathbf{F E}}{R T}\right]$ & 2 & 1 & 1 & 1 & 1 \\
\hline 5 & $r_{3}=k_{\mathrm{a} 3} \frac{k_{\mathrm{f}} k_{\mathrm{a} 1}}{k_{\mathrm{b}} k_{\mathrm{c} 1}}\left(C_{\mathrm{RS}}\right)^{2} \exp \left[\frac{\left(2-\beta_{3}\right) \mathbf{F E}}{R T}\right]-k_{\mathrm{c} 3}\left(C_{\mathrm{RSSR}}\right) \exp \left[-\frac{\beta_{3} \mathbf{F E}}{R T}\right]$ & 2 & 1 & $2-\beta_{3}$ & $\beta_{3}$ & 1 \\
\hline 6 & $r_{1}=k_{\mathrm{f}}\left(C_{\mathrm{RS}-}\right)^{2}-k_{\mathrm{b}} \frac{k_{\mathrm{c} 2} k_{\mathrm{c} 3}}{k_{\mathrm{a} 2} k_{\mathrm{a} 3}}\left(C_{\mathrm{RSSR}}\right) \exp \left[-\frac{2 \mathrm{~F} E}{R T}\right]$ & 2 & 1 & 0 & 2 & 1 \\
\hline 7 & $r_{2}=k_{\mathrm{a} 2} \frac{k_{\mathrm{f}}}{k_{\mathrm{b}}}\left(C_{\mathrm{RS}}\right)^{2} \exp \left[\frac{\left(1-\beta_{2}\right) \mathbf{F E}}{R T}\right]-k_{\mathrm{c} 2} \frac{k_{\mathrm{c} 3}}{k_{\mathrm{a} 3}}\left(C_{\mathrm{RSSR}}\right) \exp \left[-\frac{\left(1+\beta_{2}\right) \mathbf{F E}}{R T}\right]$ & 2 & 1 & $1-\beta_{2}$ & $1+\beta_{2}$ & 1 \\
\hline 8 & $r_{2}=k_{\mathrm{a} 2} \frac{k_{\mathrm{a} 1}}{k_{\mathrm{cl}}} C_{\mathrm{RS}}-\exp \left[\frac{\left(2-\beta_{2}\right) \mathbf{F E}}{R T}\right]-k_{\mathrm{c} 2} \frac{k_{\mathrm{b}}}{k_{\mathrm{f}}} \frac{C_{\mathrm{RSSR}}}{C_{\mathrm{RS}^{-}}} \exp \left[-\frac{\beta_{2} \mathbf{F} E}{R T}\right]$ & 1 & 1 & $2-\beta_{2}$ & $\beta_{2}$ & 1 \\
\hline 9 & $r_{3}=k_{\mathrm{f}} \frac{k_{\mathrm{a} 1} k_{\mathrm{a} 2}}{k_{\mathrm{c} 1} k_{\mathrm{c} 2}} C_{\mathrm{RS}^{-}}{ }^{2} \exp \left[\frac{2 \mathrm{FE}}{R T}\right]-k_{\mathrm{b}} C_{\mathrm{RSSR}}$ & 2 & 1 & 2 & 0 & 1 \\
\hline
\end{tabular}

$$
\begin{aligned}
& { }^{{ }^{a} \gamma_{R^{-}}}=\left(\frac{\partial \ln \left(i_{\mathrm{a}}\right)}{\partial \ln \left(C_{\mathrm{RS}^{-}}\right)}\right)_{\mathrm{CRSSR}_{\mathrm{RS}} E} \\
& { }^{\mathrm{b}} \gamma_{\mathrm{RSSR}}=\left(\frac{\partial \ln \left(i_{\mathrm{c}}\right)}{\partial \ln \left(C_{\mathrm{RSSR}}\right)}\right)_{\mathrm{CRS}^{-}, E}
\end{aligned}
$$

Under the condition that the electrode reaction is completely controlled by kinetics, i.e., mass transfer is sufficiently fast to ensure that the concentration of the electroactive species at the electrode surface is identical to the bulk concentration, Eq. [2] can be reduced to the ButlerVolmer equation

$$
i_{\mathrm{k}}=i_{\mathrm{o}}\left\{\exp \left(\alpha_{\mathrm{a}} \mathbf{F} \boldsymbol{\eta} / R T\right)-\exp \left(-\alpha_{c} \mathbf{F}_{\eta} / R T\right)\right\}
$$

\section{Mechanistic Analysis $(15,16)$}

Listed in Table I are a number of possible reaction pathways considered in the analysis, EC, ECE, CEE, and EEC routes, together with the corresponding reaction mechanisms. The kinetic parameters associated with each mechanism, such as reaction orders, transfer coefficients, and dependence of exchange current densities on concentration, can be derived as follows.

First, assume the reaction takes the EC route (see Table I). Then, the reaction rate for each elementary step can be expressed as (15)

$$
\begin{gathered}
r_{\mathrm{I}}=i_{1} / \mathbf{F}=k_{\mathrm{a} 1} C_{\mathrm{RS}-} \exp \left[\left(1-\beta_{1}\right) \mathbf{F E} / R T\right] \\
\quad-k_{\mathrm{cl}} C_{\mathrm{RS}} \exp \left[-\beta_{1} \mathbf{F} E / R T\right] \\
r_{2}=k_{\mathrm{f}}\left(C_{\mathrm{RS}}\right)^{2}-k_{\mathrm{b}} C_{\mathrm{RSSR}}
\end{gathered}
$$

Depending on the rate-controlling nature of each step, two possible reaction mechanisms result.

1. The first step, charge transfer, is the rate-determining step (rds) and the second step, chemical reaction, is at equilibrium. In this case, the concentration of the radical $\mathrm{RS}^{*}$ is given by

$$
\mathrm{C}_{\mathrm{RS}}=\left(k_{\mathrm{b}} / k_{\mathrm{r}} \mathrm{C}_{\mathrm{RSSR}}\right)^{1 / 2}
$$

$r_{1}=i_{1} / \mathbf{F}=k_{\mathrm{a} 1} C_{\mathrm{RS}^{-}} \exp \left[\alpha_{\mathrm{a}} \mathbf{F} E / R T\right]$

$$
-k_{\mathrm{cl}}\left(k_{\mathrm{b}} / k_{\mathrm{f}} C_{\mathrm{RSSR}}\right)^{1 / 2} \exp \left[-\alpha_{\mathrm{c}} \mathbf{F E} / R T\right] \quad[8 \mathrm{a}]
$$

or

$$
\begin{aligned}
i=i_{\mathrm{o}}\left\{\left(\mathrm{C}_{\mathrm{RS}^{-}, \mathrm{g}} / \mathrm{C}_{\mathrm{RS}^{-}, \mathrm{b}}\right)\right. & \exp \left(\alpha_{2} \mathbf{F} \eta / R T\right) \\
& \left.-\left(C_{\mathrm{RSSR}, \mathrm{s}} / C_{\mathrm{RSSR}, \mathrm{b}}\right)^{1 / 2} \exp \left(-\alpha_{\mathrm{c}} \mathbf{F}_{\eta} / R T\right)\right\}
\end{aligned}
$$

where

$$
i_{\mathrm{o}}=\mathbf{F} A k^{\mathrm{o}}\left(C_{\mathrm{RS}}\right)^{\alpha_{\mathrm{c}}}\left(C_{\mathrm{RSSR}}\right)^{\alpha_{\mathrm{\alpha}} / 2}
$$

indicating that $\mu=\alpha_{c}$ and $\lambda=\alpha_{a} / 2$. The standard rate constant can be expressed by the rate constants associated with each elementary step as

$$
k^{0}=\left(k_{\mathrm{a} 1}\right)^{\alpha_{\mathrm{c}}\left(k_{\mathrm{c} 1}\right)^{\alpha_{\mathrm{a}}}\left(k_{\mathrm{b}} / k_{\mathrm{f}}\right)^{\alpha_{\mathrm{a}} / 2}}
$$

In this case, the reaction order for species $\mathrm{RS}^{-}$and RSSR are 1 and $1 / 2$, respectively. The transfer coefficients are related to the symmetry factor as

$$
\begin{gathered}
\alpha_{c}=\beta_{1} \\
\alpha_{a}=1-\beta_{1}
\end{gathered}
$$

2. If the chemical reaction is the rds and the chargetransfer step is at equilibrium, then the overall reaction rate can be expressed as

$$
i=i_{\mathrm{o}}\left\{\left(C_{\mathrm{RS}^{-}, \mathrm{s}} / C_{\mathrm{RS}^{-}, \mathrm{b}}\right)^{2} \exp \left(2 \mathbf{F}_{\eta} / R T\right)-\left(C_{\mathrm{RSSR}^{\mathrm{s}}} / C_{\mathrm{RSSR}, \mathrm{b}}\right)\right\}
$$
where

$$
i_{o}=2 \mathbf{F} A k^{\circ} C_{\text {RSSR }}
$$

and

$$
k^{\circ}=k_{\mathrm{b}}
$$


Table III. Dependence of exchange currents on concentrations of organodisulfide/thiolate salt for the possible reaction mechanisms listed in Table 1

\begin{tabular}{|c|c|c|c|}
\hline Mechanism no. & Exchange current & $\mu^{\mathrm{a}}$ & $\lambda^{b}$ \\
\hline 1 & $i_{0}=A \mathbf{F} k^{\mathrm{O}}\left(C_{\mathrm{RS}}\right)^{\beta_{1}}\left(C_{\mathrm{RSSR}}\right)^{\frac{\left(1-\beta_{1}\right)}{2}}$ & $\beta_{1}$ & $\frac{\left(1-\beta_{1}\right)}{2}$ \\
\hline 2 & $i_{\mathrm{o}}=2 A \mathbf{F} k^{\circ} C_{\mathrm{RSSR}}$ & 0 & 1 \\
\hline 3 & $i_{\mathrm{o}}=2 A \mathbf{F} k^{\circ}\left(\mathrm{C}_{\mathrm{RS}^{-}}\right)^{\beta_{1}}\left(\mathrm{C}_{\mathrm{RSSR}}\right)^{\frac{\left(1-\beta_{1}\right)}{2}}$ & $\beta_{1}$ & $\frac{\left(1-\beta_{1}\right)}{2}$ \\
\hline 4 & $i_{\mathrm{o}}=2 A \mathrm{~F} k^{\circ} C_{\mathrm{RS}}-\left(C_{\mathrm{RSSR}}\right)^{1 / 2}$ & 1 & $1 / 2$ \\
\hline 5 & $i_{0}=2 A \mathbf{F} k^{\circ}\left(C_{\mathrm{RS}^{-}}\right)^{\beta_{3}\left(C_{\mathrm{RSSR}}\right)^{1-\frac{\beta_{3}}{2}}}$ & $\beta_{3}$ & $\left(1-\frac{\beta_{3}}{2}\right)$ \\
\hline 6 & $i_{\mathrm{o}}=2 A \mathbf{F} k^{\mathrm{o}}\left(C_{\mathrm{RS}^{-}}\right)^{2}$ & 2 & 0 \\
\hline 7 & 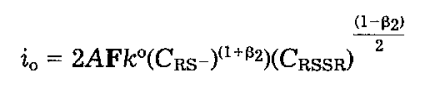 & $\left(1+\beta_{2}\right)$ & $\frac{\left(1-\beta_{2}\right)}{2}$ \\
\hline 8 & $i=2 A \mathbf{F} k^{0}\left(C_{\mathrm{RS}^{-}}\right)^{(\beta 2-1)}\left(C_{\mathrm{RSSR}}\right)^{\left(1-\frac{\beta 2}{2}\right)}$ & $\left(\beta_{2}-1\right)$ & $\left(1-\frac{\beta_{2}}{2}\right)$ \\
\hline 9 & $i=2 A \mathbf{F} k^{\circ} C_{\mathrm{RSSR}}$ & 0 & 1 \\
\hline
\end{tabular}

$$
\mathrm{a}_{\mu}=\left(\frac{\partial \ln \left(i_{0}\right)}{\partial \ln \left(C_{\mathrm{RS}^{-}}\right)}\right)_{\mathrm{CRSSR}_{\mathrm{RSR}}}
$$$$
{ }^{\mathrm{b}} \lambda=\left(\frac{\partial \ln \left(i_{0}\right)}{\partial \ln \left(C_{\mathrm{RSSR}}\right)}\right)_{\mathrm{CRS}^{-}}
$$

In this case, the reaction order for species $\mathrm{RS}^{-}$is 2 and that for species RSSR is 1 . The corresponding anodic and cathodic transfer coefficients are 2 and 0 , respectively, indicating that the reaction rate in the cathodic direction is independent of electrode potential. Further, the exponents for the concentration dependence of exchange currents are 1 for $\lambda$ and 0 for $\mu$, indicating that $i_{0}$ is independent of the concentration of thiolate anions.

Similar analyses have been performed for other possible reaction pathways, i.e., the $\mathrm{ECE}, \mathrm{CEE}$, and $\mathrm{EEC}$ routes in Table I.

The governing kinetic equations and the corresponding reaction orders, transfer coefficients, and stoichiometric coefficients for the nine possible reaction mechanisms derived from the above four possible reaction pathways have been tabulated in Table II. The corresponding expression for the exchange current and its dependence on concentration, as defined in Eq. [4], were summarized in Table III for the various reaction mechanisms.

\section{Electrochemical Methods}

Rotating disk electrode techniques (19-21).-Reaction orders for various organodisulfides and the corresponding thiolate anions were determined from the dependence of the current at an RDE on rotation speed at constant electrode potential without varying the bulk concentration (since the effective concentration of electroactive species at the surface of an RDE is a function of rotation speed).

The current at an RDE can, in general, be expressed as

$$
i=i_{1}\left[1-c_{\mathrm{i}, \mathrm{s}} / \mathrm{c}_{\mathrm{i}, \mathrm{b}}\right]
$$

where $i_{1}$ is the convective-diffusive limiting current given by

$$
i_{1}=0.62(n \mathbf{F} A) C_{\mathrm{i}, \mathrm{b}} D_{\mathrm{i}}{ }^{2 / 3} v^{-1 / 6} \omega^{1 / 2}
$$

Combining Eq. [2] and [15], one can relate the anodic or cathodic current at an $\mathrm{RDE}, i$, to $i_{\mathrm{I}}$ and $i_{\mathrm{k}}$ as

$$
i / i_{\mathrm{k}}=\left[1-i / i_{\mathrm{1}}\right]^{\mathrm{i}_{\mathrm{i}}}
$$

where $i_{\mathrm{k}}$ is the pure kinetic current (as defined in Eq. [5]). At a given potential, the kinetic current is a constant (and can be determined from extrapolation at $\omega \rightarrow \infty$ ). The reaction order for species $i, \gamma_{\mathrm{i}}$, can be expressed as

$$
\gamma_{\mathrm{RS}^{-}}=d\left[\log \left(i_{\mathrm{a}}\right)\right] / d\left[\log \left(1-i_{\mathrm{a}} / i_{1, \mathrm{a}}\right)\right]
$$

and

$$
\gamma_{\mathrm{RSRS}}=d\left[\log \left(i_{\mathrm{c}}\right)\right] / d\left[\log \left(1-i_{\mathrm{c}} / i_{1, \mathrm{c}} \mathrm{c}\right)\right]
$$

where $i_{\mathrm{a}}$ (or $i_{\mathrm{c}}$ ) is the current measured at a given rotation speed and $i_{1, a}$ (or $i_{1, c}$ ) is the convective-diffusive limiting current at the same rotating speed.

When $\gamma_{i}=1$, i.e., the reaction is first order for species $i$, Eq. [16] can be rewritten as

$$
1 / i=1 / i_{\mathrm{k}}+1 / i_{1}
$$

Thus, the plot of $1 / i v s . \omega^{-1 / 2}$ at a constant potential is a straight line. The intercepts $\left(1 / i_{\mathrm{k}}\right)$ give an estimate of kinetic current $\left(i_{\mathrm{k}}\right)$ at a given potential, while the slopes $\left(d\left\{i^{-1}\right\} / d\left\{\omega^{-1 / 2}\right\}\right)$ allow assessment of the diffusion coefficients.

Polarization measurement.-Exchange currents, transfer coefficients, and stoichiometric coefficients were determined from polarization measurements at either stationary electrodes or rotating disk electrodes under experimental constraints that the electrochemical processes were completely controlled by kinetics.

When $|\eta|>>R T / \mathbf{F}$, the Tafel approximation of Eq. [5] gives

$$
i_{\mathrm{a}}=i_{\mathrm{o}} \exp \left(\alpha_{\mathrm{a}} \mathbf{F} \eta / R T\right)
$$

and

$$
i_{\mathrm{c}}=i_{\mathrm{o}} \exp \left(-\alpha_{\mathrm{c}} \mathbf{F} \eta / R T\right)
$$

The exchange currents were obtained directly from the intercepts of the Tafel plots. The anodic and cathodic transfer coefficients were calculated from the Tafel slopes. The stoichiometric coefficients were determined from the transfer coefficients and the total number of electrons involved in the overall reaction as

$$
\nu=n /\left(\alpha_{\mathrm{a}}+\alpha_{\mathrm{c}}\right)
$$

When $|\eta|<<R T / F$, linear approximation of Eq. [5] gives

$$
i_{\mathrm{k}}=i_{\mathrm{o}}\left(\alpha_{\mathrm{a}}+\alpha_{\mathrm{c}}\right)(\mathbf{F} \eta / R T)
$$




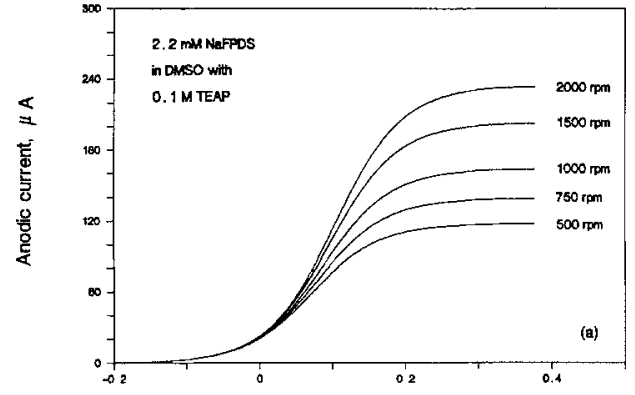

Platinum cisk potential vs $\mathrm{Ag} / \mathrm{AgCl}$ (V)

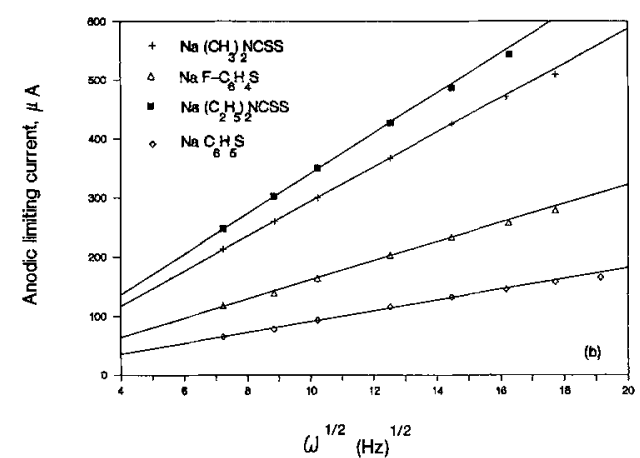

Fig. 1. (a) Linear sweep voltammograms for oxidation of $\mathrm{FPT}^{-}$to FPDS at a platinum disk electrode immersed in electrolyte solution of $2.2 \mathrm{mM}$ NaFPT in DMSO containing 0.1M TEAP (293 K). The potential sweep rate was $5 \mathrm{mV} / \mathrm{s}$. The numbers adjacent to each curve correspond to rotation speeds in rpm. (b) Levich plots for oxidation of various thiolate anions to the corresponding disulfide at a platinum electrode. The bulk concentration of thiolate salt in the electrolyte solution was (G) $2.8 \mathrm{mM} \mathrm{NaDEDC,}$ (+) $2.4 \mathrm{mM} \mathrm{NaDMDC,}(\triangle) 2.2 \mathrm{mM}$ NaFPT, and $(\diamond) 2.1 \mathrm{mM}$ NaPT.

The slope of the linear plot of $i_{\mathrm{k}}$ against $\eta$ allows determination of the exchange current, $i_{\mathrm{o}}$. The standard rate constants were calculated from $i_{0} s$ using Eq. [4].

The dependence of the exchange current on concentration was further used to verify the transfer coefficients and the reaction mechanism. The theoretical values of $\mu$ and $\lambda$ corresponding to different reaction mechanisms are tabulated in Table III.

\section{Results and Discussion}

Reaction order (mechanism determination).-Linear sweep voltammograms at a platinum disk electrode, rotated at different rates, are shown in Fig. la for oxidation of the thiolate anion FPT $^{-}$to the disulfide FPDS. The convective-diffusive limiting currents in the anodic direction, $i_{1, a}$, are shown in Fig. $1 \mathrm{~b}$ for oxidation of various thiolate anions to the corresponding disulfides. The slight deviation from linearity, particularly at high rotation rates, was probably due to the distortion of the hydrodynamic layer near the disk electrode by turbulent flow. The measured solution viscosity and calculated diffusion coefficients of the thiolate anions in the electrolyte solution are tabulated in Table IV.

The plots of $\log i_{\mathrm{a}} v \mathrm{~s} . \log \left(1-i_{\mathrm{a}} / i_{\mathrm{l}, \mathrm{a}}\right)$ for oxidation of $\mathrm{FPT}^{-}$ to FPDS at constant potentials and different rotation speeds are shown in Fig. 2a. The slope of the plots at different potentials represents the observed anodic order, $\gamma_{\mathrm{FPT}^{-}}$, for species FPT ${ }^{-}$.

As analyzed in the previous section and shown in Table II, the anodic reaction order for species $\mathrm{RS}^{-}$should be either 1 or 2 for the mechanisms considered. The observed reaction orders, averaged over values obtained at different potentials from plots similar to Fig. 2a, are listed in Table $V$ for oxidation of various thiolate anions. The experimental values of $\gamma_{R^{-}}$are reasonably close to unity indicating that the oxidation of $\mathbf{R S}^{-}$to RSSR is a first-order reaction. In addition, the linear relationship between $i^{-1}$ and $\omega^{-1 / 2}$ at constant potentials, as shown in Fig. 3a, further confirms that the anodic order for species $\mathrm{RS}^{-}$is one. This
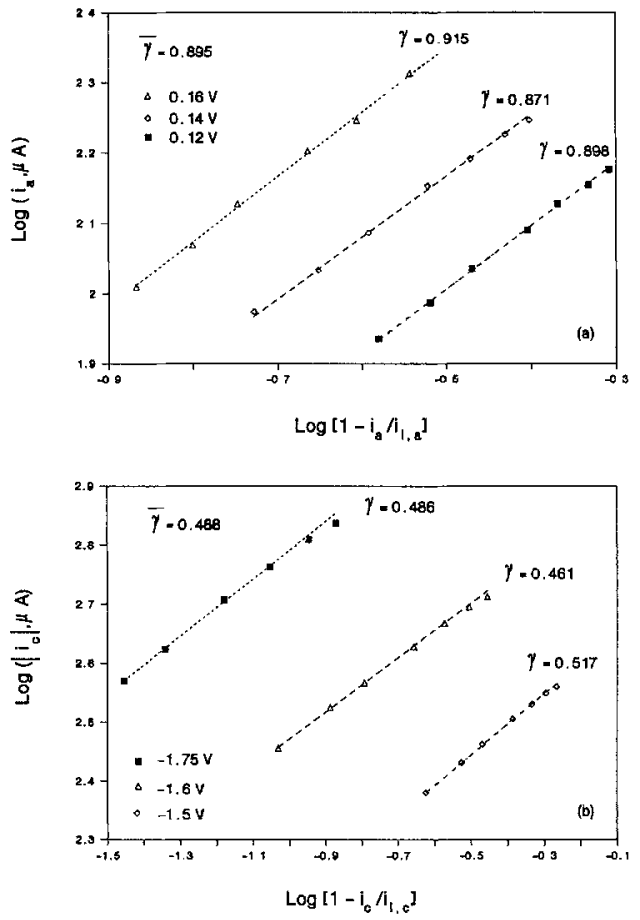

Fig. 2. (a) The plot of $\log \left(i_{0}\right) v s . \log \left(1-i_{a} / i_{1,0}\right)$ at different rotation speeds for oxidation of thiolate anion $\mathrm{FPT}^{-}$to disulfide FPDS at a platinum disk electrode at constant potentials. The slopes of the linear plots, $\gamma$, represent the anodic reaction order for species FPT ${ }^{-}$. Electrolyte solution contained $2.2 \mathrm{mM}$ NaFPT. (b) The plot of $\log \left(i_{c}\right)$ vs. $\log$ $\left(1-i_{c} / i_{1, c}\right)$ at different rotation speeds for reduction of disulfide FPDS to thiolate anion $\mathrm{FPT}^{-}$at a platinum disk electrode at constant potentials. The slopes of the linear plots, $\gamma$, represent the cathodic reaction orders for species FPDS. Electrolyte solution contained 2.0 mM FPDS.

observation strongly suggests that reaction mechanisms with an anodic reaction order of 2 are very unlikely, and the only plausible mechanisms left are those with oxidation reaction orders of 1, i.e., mechanism 1,3 , and 8 .

Similarly, shown in Fig. $2 \mathrm{~b}$ are the plots of $\log \left|i_{\mathrm{c}}\right| v s . \log \left[1-i_{\mathrm{c}} i_{\mathrm{l}, \mathrm{c}}\right]$ at different potentials for reduction of TETD to DEDC ${ }^{-}$. The slopes or cathodic reaction orders obtained from similar plots for various disulfides are tabulated in Table $V$. The observed values are very close to 0.5 indicating that the reduction of RSSR to RS is a half-order reaction.

Accordingly, the determination of reaction orders, in this case, uniquely suggests that the electrode reaction takes the EC route with the first step, charge transfer, as the rate-determining step, i.e.

Table IV. Calculated diffusion coefficients of thiolate anions (from RDE measurements at $293 \mathrm{~K}$ )

\begin{tabular}{lccc}
\hline $\begin{array}{c}\text { Thiolate } \\
\text { anion }\end{array}$ & $\begin{array}{c}\mathrm{C}_{\mathrm{RS}^{-}} \\
\left(\mu \mathrm{mol} \mathrm{cm}^{-3}\right)\end{array}$ & $\begin{array}{c}\text { Viscosity } \\
\left(\mathrm{cm}^{2} \mathrm{~s}^{-1}\right)\end{array}$ & $\begin{array}{c}\text { Diffusion coefficient } \\
\left(10^{-6} \mathrm{~cm}^{2} \mathrm{~s}^{-1}\right)\end{array}$ \\
\hline DEDC $^{-}$ & 2.8 & 0.02178 & $3.13 \pm 0.28$ \\
DMDC $^{-}$ & 2.4 & 0.02165 & $3.17 \pm 0.21$ \\
$\mathrm{FPT}^{-}$ & 2.2 & 0.02183 & $1.48 \pm 0.10$ \\
PT $^{-}$ & 2.1 & 0.02214 & $0.67 \pm 0.06$
\end{tabular}

Table $V$. Observed reaction orders and anodic transfer coefficients for organodisulfide/thiolate redox couples at platinum electrode (determined from RDE measurements at $293 \mathrm{~K}$ )

\begin{tabular}{lccc}
\hline & \multicolumn{2}{c}{ Reaction order } & Transfer coefficient \\
\cline { 2 - 3 } RSSR/RS $^{-}$ & $\gamma_{\mathrm{RS}}{ }^{-}$ & $\gamma_{\mathrm{RSSR}}$ & \\
\hline TETD/DEDC $^{-}$ & $0.91 \pm 0.05$ & $0.49 \pm 0.01$ & $0.65 \pm 0.017$ \\
TMTD/DMDC $^{-}$ & $0.87 \pm 0.06$ & $0.49 \pm 0.03$ & $0.64 \pm 0.027$ \\
FPDS/FPT $^{-}$ & $0.89 \pm 0.03$ & $0.51 \pm 0.02$ & $0.51 \pm 0.019$ \\
PDS/PT & $0.90 \pm 0.04$ & $0.53 \pm 0.03$ &
\end{tabular}


Table VI. Observed transfer coefficients, stoichiometric coefficients, and standard rate constants for organodisulfide/thiolate redox couples at platinum electrodes (determined from polarization measurements at $293 \mathrm{~K}$ )

\begin{tabular}{|c|c|c|c|c|c|c|c|}
\hline \multirow[b]{2}{*}{ RSSR/RS $^{-}$} & \multicolumn{2}{|c|}{$\begin{array}{l}\text { Concentration } \\
\left.(\mu \mathrm{mol} \mathrm{cm})^{-3}\right)\end{array}$} & \multirow{2}{*}{$\frac{\begin{array}{c}\text { Equilibrium } \\
\text { potential }\end{array}}{E_{\mathrm{eq}}(\mathrm{V})}$} & \multicolumn{2}{|c|}{ Transfer coefficient } & \multirow{2}{*}{$\frac{\begin{array}{c}\text { Stoichiometric } \\
\text { coefficient }\end{array}}{v}$} & \multirow{2}{*}{$\begin{array}{c}\begin{array}{c}\text { Standard rate } \\
\text { constant }\end{array} \\
k^{o} \times 10^{8}\end{array}$} \\
\hline & $\mathrm{C}_{\mathrm{RSSR}}$ & $\overline{\mathrm{C}_{\mathrm{RS}}{ }^{-}}$ & & $\alpha_{a}$ & $\alpha_{c}$ & & \\
\hline $\begin{array}{l}\text { TETD/DEDC } \\
\text { TMTD/DMDC } \\
\text { FPDS/FPT } \\
\text { PPDPT } \\
\text { PDS/PT }^{-}\end{array}$ & $\begin{array}{l}2.1 \\
2.6 \\
2.0 \\
1.8\end{array}$ & $\begin{array}{l}2.2 \\
2.4 \\
2.2 \\
2.1\end{array}$ & $\begin{array}{l}-0.260 \pm 0.009 \\
-0.256 \pm 0.012 \\
-0.397 \pm 0.014 \\
-0.512 \pm 0.011\end{array}$ & $\begin{array}{l}0.66 \pm 0.006 \\
0.67 \pm 0.011 \\
0.51 \pm 0.007 \\
0.42 \pm 0.009\end{array}$ & $\begin{array}{l}0.36 \pm 0.005 \\
0.34 \pm 0.006 \\
0.52 \pm 0.006 \\
0.56 \pm 0.011\end{array}$ & $\begin{array}{l}2 \pm 0.021 \\
2 \pm 0.025 \\
2 \pm 0.031 \\
2 \pm 0.034\end{array}$ & $\begin{array}{l}0.34 \pm 0.08 \\
1.11 \pm 0.14 \\
0.63 \pm 0.12 \\
0.51 \pm 0.06\end{array}$ \\
\hline
\end{tabular}

$$
\begin{gathered}
2\left[\mathrm{RS}^{-} \rightarrow \mathrm{RS}^{*}+e^{-}\right] \\
\mathrm{RS}^{-}+\mathrm{RS}^{*} \rightleftarrows \mathrm{RSSR}
\end{gathered}
$$

Transfer coefficient, rate constant, and stoichiometric coefficient.-Shown in Fig. 3b are the Tafel plots constructed from the kinetic currents $\left(i_{\mathrm{k}, \mathrm{a}}\right)$ obtained at $\omega \rightarrow \infty$ for oxidation of RS ${ }^{-}$to RSSR. The kinetic currents in the anodic direction, $i_{\mathrm{k}, \mathrm{a}}$, were determined from the intercepts with the $i^{-1}$ axis in the reciprocal Levich plot (i.e., $i^{-1} v s . \omega^{-1 / 2}$ ) as shown in Fig. 3a. The anodic transfer coefficients, calculated from the Tafel slopes are listed in Table V. Since the reduction of RSSR to RS- is a half-order reaction, the plot of $i^{-1} v s . \omega^{-1 / 2}$ for reduction is not a straight line (Eq. [18] is not valid) and hence the kinetic current in the cathodic direction, $i_{k, c}$, cannot be extrapolated from a plot similar to those for the anodic kinetic current. Instead, the cathodic kinetic currents were approximated by the currents directly measured at an $\mathrm{RDE}$ while increasing the rotation speed up to $3000 \mathrm{rpm}$; at low overpotentials $i_{\mathrm{k}}$ is well below $i_{1}$, so that the approximation is adequate.

Shown in Fig. 4a are the currents directly measured at a platinum RDE for various organodisulfide/thiolate redox couples. The deviation from linear Tafel behavior observed at high overpotentials was brought about by masstransfer limitations. At these potentials, electrode kinetics were sufficiently rapid so that mass transport of the elec-
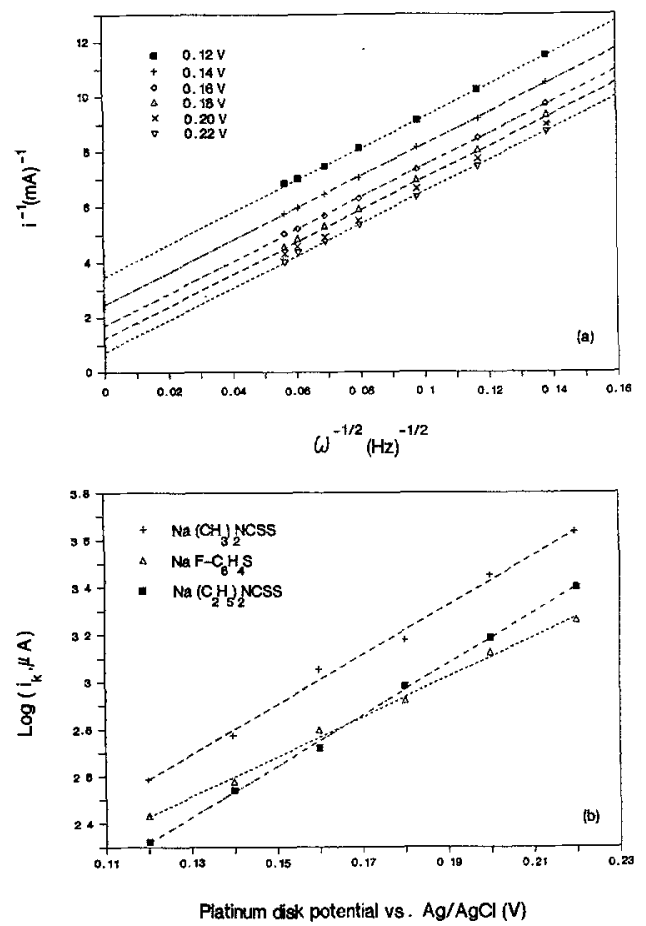

Fig. 3. (a) The reciprocal Levich plot for oxidation of thiolate anion FPT $^{-1}$ to the corresponding disulfide FPDS at a platinum electrode. Electrolyte solution contained $2.2 \mathrm{mM}$ NaFPT. (b) Tafel plots for oxidation of various thiolate anions to the corresponding disulfides at a platinum electrode $(293 \mathrm{~K})$. The kinetic currents, $i_{k}$, were determined from the intercept at $i^{-1}$ axis from the reciprical Levich plots similar to Fig. $3 a$. The bulk concentration of thiolate salt in the electrolyte solution was (a) $2.8 \mathrm{mM} \mathrm{NaDEDC},(+) 2.4 \mathrm{mM} \mathrm{NaDMDC}$, and $(\triangle) 2.2 \mathrm{mM} \mathrm{NaFPT}$. troactive species to and from the electrode surface was unable to maintain the surface concentration close to the bulk concentration. Still, there does exist a sufficiently wide potential range over which Tafel behavior prevails and the Tafel slopes are well defined. The transfer coefficients and stoichiometric coefficients calculated from these Tafel slopes within this range and the standard rate constants estimated from the intercepts are tabulated in Table VI for different RSSR/RS ${ }^{-}$couples.

The experimentally determined transfer coefficients and stoichiometric coefficients further confirm that the electrode reaction is correctly described by Eq. [22] (mechanism 1).

Concentration dependence-Polarization measurements were also performed on electrolyte solutions having various concentrations of organodisulfides and their corresponding thiolate salts. Cell currents between a platinum disk working electrode and a platinum counterelectrode were measured at rotation speed of $3000 \mathrm{rpm}$. The exchange currents were then determined from the intercepts of the corresponding Tafel plots and the slopes of the linear polarization plots.

Figure 5a shows the dependence of $i_{\mathrm{o}}$ on $\mathrm{C}_{\mathrm{RS}}$ - for various redox couples at a constant bulk concentration of organodisulfide. The slopes of the plots, $d\left\{\log \left(i_{o}\right)\right\} / d\left\{\log \left(C_{\mathrm{RS}^{-}}\right)\right\}$, directly yield the kinetic parameter $\mu$. Figure $5 \mathrm{~b}$ shows the dependence of $i_{0}$ on $C_{\mathrm{RSSR}}$ at a constant concentration of the corresponding thiolate salt. The slopes of these plots, $d\left\{\log \left(i_{\mathrm{o}}\right)\right\} / d\left\{\log \left(C_{\mathrm{RSSR}}\right)\right\}$, allows estimation of the kinetic parameter $\lambda$. Deviations from linearity indicate that the
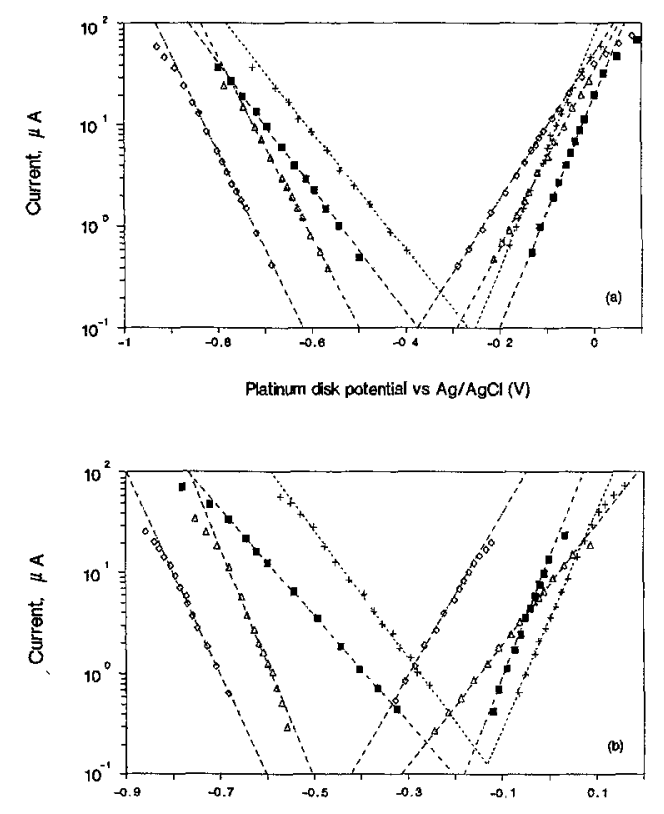

Glassy carbon disk potential vs Ag/AgCl(V)

Fig. 4. Tafel plots for various RSSR/RS- redox couples at (a) a platinum disk electrode and (b) a glassy carbon electrode. The working electrodes were rotated at $3000 \mathrm{rpm}$. The potential sweep rate was $1 \mathrm{mV} / \mathrm{s}$. The electrolyte solution contained bulk concentrations of $(\boldsymbol{D})$ $2.1 \mathrm{mM}$ TETD and $2.2 \mathrm{mM}$ NaDEDC, (+) $2.6 \mathrm{mM}$ TMTD and $2.4 \mathrm{mM}$ $\mathrm{NaDMDC},(\triangle) 2.0 \mathrm{mM}$ FPDS and $2.2 \mathrm{mM} \mathrm{NaFPT}$, and $(\diamond) 1.8 \mathrm{mM}$ PDS and $2.1 \mathrm{mM}$ NaPT. 

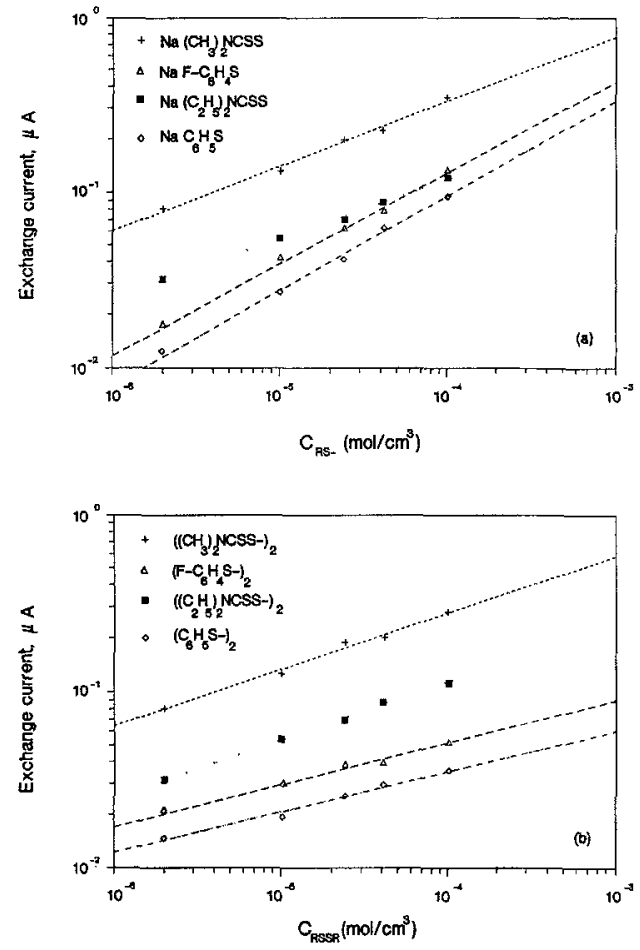

Fig. 5. (a) Dependence of exchange currents on concentration of thiolate anions at constant concentration of the corresponding organodisulfide: (ロ) $4.0 \mathrm{mM}$ TETD, (+) $4.0 \mathrm{mM}$ TMTD, $(\triangle) 4.0 \mathrm{mM}$ FPDS, and $(\diamond) 4.0 \mathrm{mM}$ PDS. (b) Dependence of exchange currents on concentration of organodisulfides at a constant concentration of the corresponding thiolate salt: (ए) $4.0 \mathrm{mM} \mathrm{NaDEDC},(+) 4.0 \mathrm{mM} \mathrm{NaDMDC}$, $(\triangle) 4.0 \mathrm{mM} \mathrm{NaFPT}$, and $(\diamond) 4.0 \mathrm{mM} \mathrm{NaPT}$.

exponents, $\mu$ and $\lambda$, or the transfer coefficients vary slightly at different concentrations. Nevertheless, the average values, as listed in Table VII, agree reasonably well with the transfer coefficients as determined from the Tafel slopes. Also, the observed exponents closely match the theoretical values for mechanism 1 (Table III), supplying further evidence for the validity of this mechanism.

Electrode materials.-Tafel plots for various redox couples at a glassy carbon RDE are shown in Fig. 4b. The experimental conditions were identical to those for the measurements at a platinum electrode as shown in Fig. 4a. The estimated transfer coefficients, stoichiometric coefficients, and standard rate constants are summarized in Table VIII. Comparison with the behavior observed at platinum electrodes, allows several conclusions: (i) for the redox couples TETD/DEDC ${ }^{-}$and TMTD/DMDC ${ }^{-}$, the equilibrium potentials established at a glassy carbon electrode $\left(E_{\mathrm{eq}}\right)$ were shifted in the positive direction with respect to those at a platinum electrode, indicating that stronger adsorption of the thiolate anions occurs on graphite than on platinum; ( $i$ i) for FPDS/FPT ${ }^{-}$and PDS/PT ${ }^{-}$, however, the equilibrium potentials were shifted in the negative direction, indicating that stronger adsorption of these organodisulfides takes place on glassy carbon than on platinum; (iii) the exchange current densities at glassy carbon electrodes are higher than those at platinum electrodes, and are modified somewhat by the $R$ group in the RSSR molecule.

Although all working electrodes were polished to a mirror finish before each run, it is conceivable that some electrodes might have partially passivated or adsorbed chemical species upon immersion into the electrolyte solutions. Thus, the electroactive surface area of the electrode might be different from its geometric surface area. Throughout this study, the surface area dependant parameters determined at each electrode were based on the geometric surface area of the electrode and therefore are apparent parameters; these values are probably more valuable in predicting actual device behavior than parameters based on absolute surface areas.
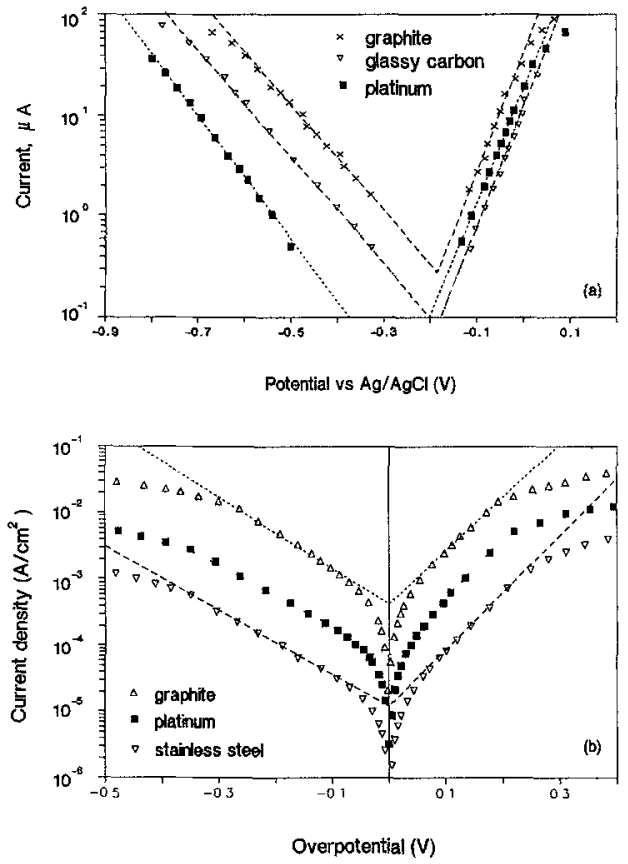

Fig. 6. Tafel plots for the TETD/DEDC redox couple of $293 \mathrm{~K}$. The platinum and glassy carbon electrodes were rotated at $3000 \mathrm{rpm}$. The graphite electrode was held stationary while the electrolyte solution was vigorously stirred during measurements. Electrolyte solution included $2.0 \mathrm{mM}$ TETD and $2.0 \mathrm{mM}$ MaDEDC. (b) Tafel plots for the TETD/DEDC ${ }^{-}$redox couple at $373 \mathrm{~K}$. Cell currents were monitored across stationary electrodes of platinum, graphite, and stainless steel while the electrolyte solution was stirred vigorously and purged with dry argon. Electrolyte solutions included 1.34M TETD and 1.34M MaDEDC. The established equilibrium potentials were $-0.349 \mathrm{~V}$ at platinum $(\square),-0.313 \mathrm{~V}$ at graphite $(\triangle)$, and $-0.348 \mathrm{~V}$ at stainless steel $(\nabla)$.

Tafel plots for TETD/DEDC ${ }^{-}$at platinum, graphite, and glassy carbon electrodes are compared in Fig. 6a. An immediate observation is that the exchange current densities or rate constants at graphite electrodes are about an order of magnitude higher than that at platinum electrodes. This is in agreement with a previous cyclic voltammetry study (6), where the separations of peak potentials at graphite electrodes were much smaller than at platinum electrodes. Also, the shift of the equilibrium potential from $-0.260 \mathrm{~V}$ at a platinum electrode to $-0.187 \mathrm{~V}$ at a glassy carbon electrode can be explained by stronger adsorption of thiolate anions at graphite or glassy carbon relative to platinum (6). Further, the measured transfer coefficients at platinum electrodes were slightly more symmetric than those at glassy carbon electrodes. In addition, the apparent exchange current densities at graphite electrodes are much higher (more than three times) than those at glassy carbon electrodes. This may be partially explained as being due to a slightly rougher surface of the graphite electrode than that of the glassy carbon electrode. However, since both electrodes were carefully polished before experimentation (hence the difference in their surface areas cannot fully account for the large difference in their apparent exchange current densities), it is likely that the chemical nature of the surfaces exerts a strong effect on electrode kinetics.

Table VII. Dependence of exchange currents at platinum electrode on concentrations of organodisùlfides/thiolate salts (determined from polarization measurements at $293 \mathrm{~K}$ )

\begin{tabular}{|c|c|c|}
\hline \multirow[b]{2}{*}{ RSSR/RS ${ }^{-}$} & \multicolumn{2}{|c|}{ Exponents } \\
\hline & $\lambda$ & $\mu$ \\
\hline TETD/DEDC ${ }^{-}$ & $0.33 \pm 0.02$ & $0.34 \pm 0.03$ \\
\hline TMTD/DMDC & $0.32 \pm 0.03$ & $0.37 \pm 0.04$ \\
\hline FPDS/FPT ${ }^{-}$ & $0.24 \pm 0.03$ & $0.52 \pm 0.05$ \\
\hline $\mathrm{PDS} / \mathrm{PT}^{-}$ & $0.23 \pm 0.04$ & $0.54 \pm 0.03$ \\
\hline
\end{tabular}



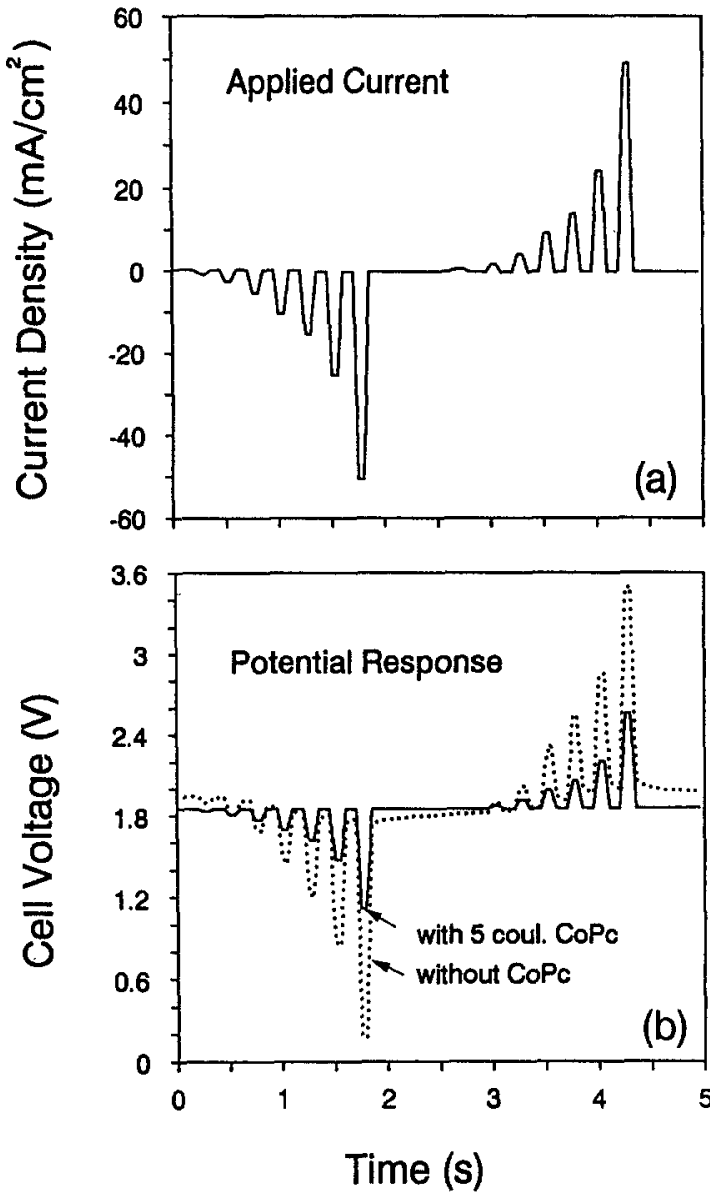

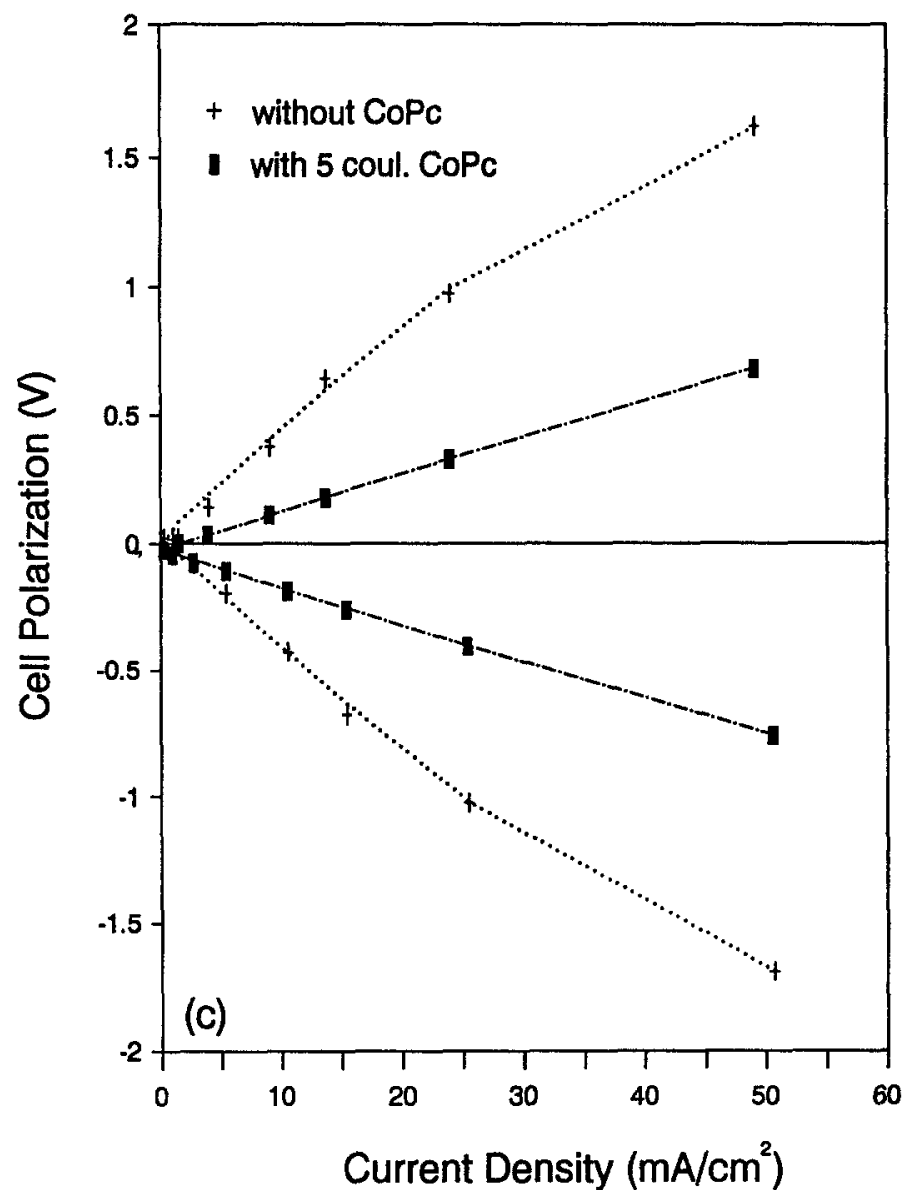

Current Density $\left(\mathrm{mA} / \mathrm{cm}^{2}\right)$

Fig. 7. Polarization behavior of $\mathrm{Na} / \beta^{\prime \prime}$-alumina/RSSR cells (cell capacity: $2000 \mathrm{C}$ ) with dimethyldisulfide (DMDS) cathodes (at $378 \mathrm{~K}$ ): (a) applied sequential transient current pulses, (b) the corresponding cell potential response, and (c) cell polarization obtained from pulse polarization measurements.

Tafel polarization of platinum, graphite, and stainless steel electrodes in concentrated RSSR/RS ${ }^{-}$solutions at $373 \mathrm{~K}$ are shown in Fig. 6b. The cell currents were measured at stationary electrodes while the electrolyte solution was vigorously stirred by a magnetic spin bar. The potential range over which Tafel polarization was observed was narrow, and deviations at high overpotentials were probably brought about by insufficient mass transport. Nevertheless, in conjunction with the determination of exchange current densities from the slopes of the corresponding linear polarization plots ( $i$ vs. $\eta$ when $|\eta|<<R T / F)$, the Tafel slopes were determined without ambiguity. The estimated transfer coefficients and the standard rate constants for different electrode materials, averaged over values obtained at different concentrations of TETD and NaDEDC, are summarized in Table IX.

In addition to inert electrodes such as platinum and carbon, stainless steel, aluminum, and copper electrodes were also investigated. Stainless steel electrodes were found to passivate quickly in the electrolyte solution and subsequently behave like platinum electrodes, but the measured exchange current densities were much lower.

Upon immersion of an aluminum electrode in an electrolyte solution containing 1.34M TETD and 1.34M NaDEDC in DMSO at $373 \mathrm{~K}$, an initial corrosion potential of $-1.6 \mathrm{~V}$ was observed, which decayed to approximately $-0.36 \mathrm{~V}$ in about $3 \mathrm{~min}$, and then remained relatively stable. The exchange current at a passivated aluminum electrode was

Table VIII. Observed transfer coefficients, stoichiometric coefficients, and standard rate constants for organodisulfide/thiolate redox couples at glassy carbon electrodes (determined from polarization measurements at $293 \mathrm{~K}$ )

\begin{tabular}{|c|c|c|c|c|c|c|c|}
\hline \multirow[b]{2}{*}{ RSSR/RS ${ }^{-}$} & \multicolumn{2}{|c|}{$\begin{array}{c}\text { Concentration } \\
\left(\mu \mathrm{mol} \mathrm{cm}^{-3}\right)\end{array}$} & \multirow{2}{*}{$\frac{\begin{array}{c}\text { Equilibrium } \\
\text { potential }\end{array}}{E_{\mathrm{eq}}(\mathrm{V})}$} & \multicolumn{2}{|c|}{ Transfer coefficient } & \multirow{2}{*}{$\frac{\begin{array}{c}\text { Stoichiometric } \\
\text { coefficient }\end{array}}{v}$} & \multirow{2}{*}{$\frac{\begin{array}{c}\text { Standard rate } \\
\text { constant }\end{array}}{k^{0} \times 10^{8}}$} \\
\hline & $\overline{C_{\text {RSSR }}}$ & $\overline{\mathrm{CRS}^{-}}$ & & $\alpha_{a}$ & $\alpha_{\mathrm{c}}$ & & \\
\hline $\begin{array}{l}\text { TETD/DEDC } \\
\text { TMTD/DMDC } \\
\text { FPDS/FPT } \\
\text { PDS/PT }^{-}\end{array}$ & $\begin{array}{l}2.1 \\
2.6 \\
2.0 \\
1.8\end{array}$ & $\begin{array}{l}2.2 \\
2.4 \\
2.2 \\
2.1\end{array}$ & $\begin{array}{l}-0.187 \pm 0.013 \\
-0.133 \pm 0.011 \\
-0.441 \pm 0.009 \\
-0.523 \pm 0.012\end{array}$ & $\begin{array}{l}0.69 \pm 0.007 \\
0.63 \pm 0.013 \\
0.35 \pm 0.011 \\
0.47 \pm 0.013\end{array}$ & $\begin{array}{l}0.31 \pm 0.006 \\
0.37 \pm 0.007 \\
0.67 \pm 0.019 \\
0.59 \pm 0.016\end{array}$ & $\begin{array}{l}2 \pm 0.013 \\
2 \pm 0.021 \\
2 \pm 0.051 \\
2 \pm 0.065\end{array}$ & $\begin{array}{r}0.89 \pm 0.13 \\
1.8 \pm 0.16 \\
2.3 \pm 0.14 \\
1.62 \pm 0.12\end{array}$ \\
\hline
\end{tabular}

Table IX. Observed transfer coefficients and standard rate constants for TETD/DEDC ${ }^{-}$at different electrode materials

\begin{tabular}{|c|c|c|c|c|}
\hline \multirow{2}{*}{$\begin{array}{l}\text { Electrode } \\
\text { material }\end{array}$} & \multicolumn{2}{|c|}{ Transfer coefficient } & \multicolumn{2}{|c|}{ Standard rate constant } \\
\hline & $\alpha_{\mathrm{a}}$ & $\alpha_{\mathrm{c}}$ & $k^{0} \times 10^{8}(293 \mathrm{~K})$ & $k^{0} \times 10^{7}(373 \mathrm{~K})$ \\
\hline $\begin{array}{l}\text { Platinum } \\
\text { Glassy carbon }\end{array}$ & $\begin{array}{l}0.65 \pm 0.009 \\
0.67 \pm 0.015\end{array}$ & $\begin{array}{l}0.35 \pm 0.008 \\
0.33 \pm 0.013\end{array}$ & $\begin{array}{l}0.34 \pm 0.09 \\
0.91 \pm 0.16\end{array}$ & $1.25 \pm 0.28$ \\
\hline $\begin{array}{l}\text { Graphite } \\
\text { Stainless steel }\end{array}$ & $\begin{array}{l}0.67 \pm 0.021 \\
0.64 \pm 0.021\end{array}$ & $\begin{array}{l}0.33 \pm 0.023 \\
0.36 \pm 0.018\end{array}$ & $2.96 \pm 0.44$ & $\begin{array}{l}9.45 \pm 0.86 \\
0.24 \pm 0.056\end{array}$ \\
\hline
\end{tabular}




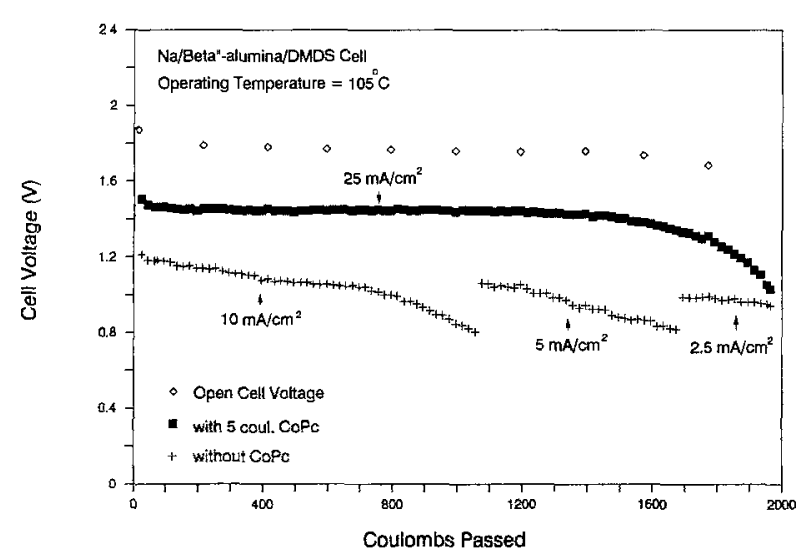

Fig. 8. Discharge curves of $\mathrm{Na} / \beta^{\prime \prime}$-alumina/RSSR cells (cell capocity: 2000C) having dimethyldisulfide (DMDS) cathodes: (I) with cobalt phthalocyonine $(5 \mathrm{C})$ electrocatalyst, $(+)$ without electrocatalyst. Cell operating temperoture was $378 \mathrm{~K}$.

about an order of magnitude lower than that at a passivated stainless steel electrode. Unlike aluminum which passivated slowly, copper electrodes were actively corroded in the electrolyte solution. As soon as a copper elec trode was immersed in the electrolyte solution, the portion of the solution adjacent to the electrode surface turned jet black (the color of the copper complex CUDEDC) and the corrosion potential shifted continuously in the positive direction as more copper was corroded.

Electrocatalysis.-The polarization behavior of a $\mathrm{Na} / \beta^{\prime \prime}$ alumina/RSSR cell with a dimethyldisulfide (DMDS) posi tive electrode, with and without cobalt phthalocyanine $(\mathrm{CoPc})$ as an electrocatalyst, is shown in Fig. 7. Sequential transient current pulses applied to the cells are shown in Fig. $7 \mathrm{a}$ and the corresponding cell potential responses are shown in Fig. 7b. Clearly, the cell polarization was dramatically reduced by introducing $\mathrm{CoPc}$, as shown in Fig. 7c. The discharge curves of these cells (Fig. 8) further demonstrate that the performance of the $\mathrm{Na} / \mathrm{RSSR}$ cell with $\mathrm{CoPc}_{\mathrm{C}}$ was greatly improved relative to the cell without CoPc. In fact, the reduction of $\mathrm{Na} / \mathrm{RSSR}$ cell overpotential by phthalocyanine addition was observed on both charge and discharge, indicating that electrocatalysis is probably due to adsorbed phthalocyanine on the graphite felt current collector. Other transition metal phthalocyanines and transition metal thio salts, including $\mathrm{Co}, \mathrm{Fe}, \mathrm{Cu}, \mathrm{Zn}$, Ti, etc., were also found to have some catalytic effect. The electrocatalysis of RSSR/RS ${ }^{-}$redox couples by adsorbed transition metal phthalocyanines has been reported previously for the related cystine/cysteine redox couple (22). The use of adsorbed phthalocyanines to enhance the activity of the graphite electrode is analogous to the use of modified electrodes for similar purposes $(23,24)$. However, further studies are needed to elucidate the detailed catalytic mechanism.

\section{Conclusions}

The observed reaction orders for the RSSR/RS ${ }^{-}$redox couples are 1 in the anodic direction and $1 / 2$ in the cathodic direction. The determined transfer coefficients are $\beta$ and $(1-\beta)$ for the cathodic and anodic process, respectively; this indicates that the rate-determining step is repeated twice $(v=2)$ for the completion of the overall reaction. The reaction pathway, therefore, takes the EC route (Table I) with the first step, charge transfer, as the rate-determining step. The kinetics of the electrode reaction, then, are fully described by Eq. [6]-[11].

The transfer coefficients and the standard rate constants for various redox couples at different electrode materials as well as at different temperatures are summarized in Tables V-IX.

Electrocatalysts, such as transition metal phthalocyanines and transition metal thiolate slates have been successfully utilized to assist charge transfer.

The high apparent exchange current densities at graphite electrodes suggested that graphite is a good positive electrode material, while the stability of stainless steel and aluminum metals towards the RSSR/RS ${ }^{-}$electrolyte solutions makes them likely candidates for cell case materials.

\section{Acknowledgments}

This work was supported by the Assistant Secretary for Conservation and Renewable Energy, Office of Energy Storage and Distribution, Energy Storage Division of the U.S. Department of Energy under Contract No. DE-AC0376 SF00098 with the Lawrence Berkeley Laboratory.

Manuscript submitted Feb. 2, 1989; revised manuscript received April 28, 1989.

The University of California, Berkeley, assisted in meeting the publication costs of this article.

\section{LIST OF SYMBOLS}

\section{Abbreviations}

$\mathrm{DEDC}^{-}$diethyl dithiocarbamate anion,

$\begin{array}{ll} & {\left[\left(\mathrm{C}_{2} \mathrm{H}_{5}\right)_{2} \mathrm{NCSS}^{-}\right.} \\ \text {DMDC }^{-} & \text {dimethyl dithiocarbamate anion, }\end{array}$

DMDS $\left.\quad\left[\mathrm{CH}_{3}\right)_{2} \mathrm{NCSS}\right]^{-}$

DMSO dimethylsulfoxide

FPDS di-fluorophenyl disulfide, $\left(\mathrm{F}-\mathrm{C}_{6} \mathrm{H}_{4}-\mathrm{S}-\right)_{2}$

$\mathrm{FPT}^{-} \quad$ fluorophenyl thiolate anion, $\left[\mathrm{F}-\mathrm{C}_{6} \mathrm{H}_{4}-\mathrm{S}\right]^{-}$

MPc metal phthalocyanine

NaDEDC sodium diethyl dithiocarbamate,

$\left(\mathrm{C}_{2} \mathrm{H}_{5}\right)_{2} \mathrm{NCSS}-\mathrm{Na}$

NaDMDC sodium dimethyl dithiocarbamate,

NaFPT $\quad\left(\mathrm{CH}_{3}\right)_{2} \mathrm{NCSS}-\mathrm{Na}$

sodium fluorophenyl thiolate, $\mathrm{F}-\mathrm{C}_{6} \mathrm{H}_{4}-\mathrm{S}-\mathrm{Na}$

NaPT

PDS

$\mathrm{PT}^{-}$

$\mathrm{R}$

RDE

rds

rpm

$\mathrm{RS}^{-}$

RSSR

TEAP

sodium phenyl thiolate, $\mathrm{C}_{6} \mathrm{H}_{5}-\mathrm{S}-\mathrm{Na}$

phenyl disulfide, $\left(\mathrm{C}_{6} \mathrm{H}_{5}-\mathrm{S}-\right)_{2}$

phenyl thiolate anion, $\left[\mathrm{C}_{6} \mathrm{H}_{5}-\mathrm{S}\right]^{-}$

an organic moiety

rotating disk electrode

rate-determining step

revolution per minute

a group of thiolate anions

a group of organic disulfides

tetraethylammonium perchlorate,

$\left(\mathrm{C}_{2} \mathrm{H}_{5}\right)_{4} \mathrm{NClO}_{4}$

TETD tetraethylthiuram disulfide, $\left(\left(\mathrm{C}_{2} \mathrm{H}_{5}\right)_{2} \mathrm{NCSS}-\right)_{2}$

TMAC tetramethylammonium chloride, $\left(\mathrm{CH}_{3}\right)_{4} \mathrm{NCl}$

TMTD tetramethylthiuram disulfide, $\left(\left(\mathrm{CH}_{3}\right)_{2} \mathrm{NCSS}-\right)_{2}$

Notation

A electrode area, $\mathrm{cm}^{2}$

$C^{*}{ }_{i} \quad$ concentration of species i $\left(i=R^{-}\right.$or RSSR $)$,

\section{$\mu \mathrm{mol} \mathrm{cm}-3$}

$C^{*}{ }_{i, s} \quad$ concentration of species $\mathrm{i}$ at electrode surface, $\mu \mathrm{mol} \mathrm{cm}^{-3}$

$C^{*}$ i,b concentration of species $i$ in the bulk solution, $\mu \mathrm{mol} \mathrm{\textrm {cm } ^ { - 3 }}$

$D_{1} \quad$ diffusion coefficient of species $\mathrm{i}, \mathrm{cm}^{2} \mathrm{~s}^{-1}$

$E$ potential of an electrode $v s$. a reference, $V$

$E_{\text {eq }} \quad$ equilibrium potential of an electrode $v s$. a ref-

erence, $V$

F Faraday's constant, $96,487 \mathrm{C}_{\text {equiv. }}^{-1}$

$i \quad$ current, $\mu$ A

$i_{\mathrm{k}} \quad$ pure kinetic current as defined by Eq. $5, \mu \mathrm{A}$

$i_{\mathrm{k}, \mathrm{a}}, i_{\mathrm{k}, \mathrm{c}} \quad$ pure kinetic current in anodic and cathodic

direction, $\mu \mathrm{A}$

$i_{1} \quad$ limiting current, $\mu \mathrm{A}$

$i_{\mathrm{l}, \mathrm{a}}, i_{\mathrm{l}, \mathrm{c}} \quad$ limifing current in anodic and cathodic direction, $\mu \mathrm{A}$

$i_{\mathrm{o}} \quad$ exchange current, $\mu \mathrm{A}$

$k^{\circ} \quad$ standard rate constant, $\left(\mathrm{mol} / \mathrm{s}-\mathrm{cm}^{2}\right)\left(\mathrm{cm}^{3} /\right.$

$k_{\mathrm{a}}, k_{\mathrm{c} 1} \quad \begin{aligned} & \text { rate constants in anodic and cathodic } \\ & \text { tion for elementary step } i(i=1,2,3)\end{aligned}$ $\mathrm{mol})^{(\lambda+\mu)}$

$k_{\mathrm{f}}, k_{\mathrm{b}} \quad$ rate constants in forward and backward direction for a chemical reaction

$n \quad$ number of electrons transferred in the overall

$r \quad \begin{array}{ll}\text { reaction }\left(n=\gamma^{-}+r v+\gamma^{-}\right) \\ \text {number of electrons transferred in the rds }\end{array}$

$r_{\mathrm{i}} \quad$ reaction rate for elementary step $i(i=1,2,3)$, $\mathrm{mol} \mathrm{cm}{ }^{-2} \mathrm{~s}^{-1}$

$R \quad$ universal gas constant, $8.3143\left[\mathrm{~J} \mathrm{~mol}^{-1} \mathrm{~K}^{-1}\right]$

$T \quad$ absolute temperature, $\mathrm{K}$

Greek

$\alpha_{a}, \alpha_{c} \quad$ transfer coefficients (as defined in Eq. [2] or [5]) 
$\beta \quad$ symmetry factor of the rds

$\beta_{\mathrm{i}} \quad$ symmetry factor of elementary step $i$ symmetry

$\gamma, r^{\leftarrow}$ number of electrons transferred in the steps preceding and after the rds (in the anodic direction)

$\gamma_{i} \quad$ reaction order for species $i\left(i=\mathrm{RS}^{-}\right.$or RSSR $)$ $\eta$ overpotential at an electrode surface, $\eta=E-E_{\text {eq }}, V$ exponents in concentration dependence of exchange current (see Eq. [4])

$v \quad$ kinematic viscosity of an electrolyte solution, $\mathrm{cm}^{2} \mathrm{~s}^{-1}$ or stoichiometric coefficient of the rate-determining step

$\omega$ rotation speed of disk working electrode, $\mathrm{Hz}$

\section{REFERENCES}

1. K. M. Abraham, R. D. Rauh, and S. B. Brummer, Electrochim. Acta, 23, 501 (1978).

2. K. M. Abraham, L. Pitts, and R. Schiff, This Journal, 127, 2545 (1980).

3. G. Mamantov, R. Marassi, M. Matsunaga, Y. Ogata, J. P. Wiaux, and E. J. Frazer, ibid., 12\%, 2319 (1980).

4. R. J. Bones, J. Coetzer, R. C. Gallowway, and D. A. Teagle, ibid., 134, 2379 (1987).

5. S. J. Visco, C. C. Mailhe, L. C. De Jonghe, and IM. B. Armand, ibid., 136, 661 (1989).

6. M. Liu, S. J. Visco, and L. C. De Jonghe, ibid., 136, 2570 (1989).

7. M. Liu, S. J. Visco, and L. C. De Jonghe, Abstract 75, p. 115, The Electrochemical Society Extended Abstracts, Vol. 88-2, Chicago, IL, Oct. 9-14, 1988.

8. S. Sarangapani and E. Yeager, in "Comprehensive Treatise of Electrochemistry," Vol. 9, Plenum Press, New York (1981).

9. M. Enyo, in "Comprehensive Treatise of Electrochem- istry," Vol. 7, Plenum Press, New York (1981).

10. M. Liu, S. J. Visco, and L. C. De Jonghe, To be submitted to This Journal.

11. V. Y. Filinovsky and Y. V. Pleskov, in "Comprehensive Treatise of Electrochemistry," Vol. 9, p. 293, Plenum Press, New York (1981).

12. F. Opekar and P. Beran, J. Electroanal. Chem., 69, 1 (1976).

13. D. Jahn and W. Vielstich, This Journal, 109, 849 (1962).

14. A. J. Bard and L. R. Faulkner, "Electrochemical Methods, Fundamentals and Applications," Wiley, New York (1980)

15. J. S. Newman, "Electrochemical Systems," PrenticeHall, Englewood Cliffs, NJ (1972).

16. J. O'M. Bockris and A. K. N. Reddy, "Modern Electrochemistry," Vol. 2, Plenum Press, New York (1970).

17. P. T. Kissinger, C. R. Preddy, R. E. Shoup, and W. R. Heineman, in "Laboratory Techniques in Electroanalytical Chemistry," Marcel Dekker, Inc., New York (1984).

18. M. W. M. Graef, This Journal, 132, 1038 (1985).

19. M. Sakai, J. Osteryoung, and R. A. Osteryoung, ibid., 135, 3001 (1988).

20. R. W. Zurilla, R. K. Sen, and E. Yeager, ibid., 125, 1103 (1978).

21. V. Veskovic, N. Anastasijevie, and R. R. Adzic, J. Electroanal. Chem., 218, 53 (1987).

22. J. H. Zagal and P. Herrera, Electrochim. Acta, 30, 449 (1985).

23. D. E. Bergbreiter in "Chemically Modified Surfaces in Catalysis and Electrocatalysis," J. S. Miller, Editors, p. 1, American Chemical Society, Washington. DC (1982).

24. R. W. Murray, Philos. Trans. R. Soc., London, Ser. A, 302, 253 (1981)

25. S. J. Visco and M. Liu, J. Appl. Electrochem., To be published.

\title{
Homogeneous and Heterogeneous Catalytic Reactions in Cobalt Oxide/Graphite Air Electrodes
}

\section{Chemical Kinetics of Peroxide Decomposition by Co(II) lons in Alkaline Solutions}

\author{
S. P. Jiang, ${ }^{1}$ Z. G. Lin, ${ }^{2}$ and A. C. C. Tseung* \\ Chemical Energy Research Center, The City University, Northampton Square, London EC1V OHB, England
}

\section{ABSTRACT}

This paper considers the role played by dissolved cobaltous ions in concentrated alkaline solutions in the homogeneous decomposition of $\mathrm{H}_{2} \mathrm{O}_{2}$ and its significance to oxygen reduction in alkaline media. Dissolved cobaltous ions, in the form of $\mathrm{HCoO}_{2}{ }^{-}$in concentrated alkaline solutions, show a very high catalytic activity for the decomposition of $\mathrm{H}_{2} \mathrm{O}_{2}$ even at a concentration of $1 \mathrm{ppm}$. The homogeneous decomposition of peroxide is not a simple first-order reaction as reported in literature but is a 1.2 order reaction. It is suggested that kinetics of decomposition of $\mathrm{H}_{2} \mathrm{O}_{2}$ in the presence of Co $3 \mathrm{O}_{4}$ is controlled by the homogeneous catalytic reaction of the $\mathrm{HCoO}_{2}^{-}$ions, the heterogeneous redox reaction between $\mathrm{HCoO}_{2}{ }^{-}$ ions in solution, and the $\mathrm{Co}^{3+}$ ions in the cobalt oxide spinel lattice sites.

Oxygen reduction on carbon, graphite, and certain metal oxides in alkaline solutions is considered to proceed through the formation of peroxide intermediate

$$
\mathrm{O}_{2}+\mathrm{H}_{2} \mathrm{O}+2 e=\mathrm{HO}_{2}^{-}+\mathrm{OH}^{-}
$$

with the standard potential of $-0.0649 \mathrm{~V}$ (vs. SHE at $25^{\circ} \mathrm{C}$ ) (1). The electroreduction of $\mathrm{H}_{2} \mathrm{O}_{2}$ is unlikely to occur at normal operating potential, and further reaction would involve the decomposition of $\mathrm{HO}_{2}{ }^{-}$if $\mathrm{HO}_{2}{ }^{-}$-decomposing catalysts are present

$$
2 \mathrm{HO}_{2}^{-}=2 \mathrm{OH}^{-}+\mathrm{O}_{2}
$$

The released oxygen is then further reduced, leading to higher efficiency and open-circuit voltage (2). The kinetics

*Electrochemical Society Active Member.

1 Present address: Chemical Energy Research Center, University of Essex, Colchester, Essex, England.

2 Present address: Department of Chemistry, Xiamen University, Xiamen, China and mechanisms of such oxygen reduction reactions have been extensively studied on various transition metal oxide/carbon or graphite electrodes. All the previous studies proposed that the peroxide intermediate is heterogeneously decomposed on the active surface sites of transition metal oxides, and the reaction was considered to be first-order (3-5).

However, it is well-known from Pourbaix diagram (6) that in alkaline solutions, cobalt oxides have a tendency to dissolve gradually in the potential range for oxygen reduction. In concentrated alkaline solution (ca. $p \mathbf{H}>10.6$ ), the dissolved cobaltous ion $\mathrm{Co}^{2+}$ is in the form of the dicobaltite ion $\mathrm{HCoO}_{2}{ }^{-}$, which is characterized by blue color (7)

$$
\mathrm{Co}^{2+}+2 \mathrm{H}_{2} \mathrm{O}=\mathrm{HCoO}_{2}^{-}+3 \mathrm{H}^{+}
$$

Efremov et al. (8) have shown that contact between $\mathrm{Co}_{3} \mathrm{O}_{4}$ and $\mathrm{KOH}$ solution leads to changes in the spinel structure, forming simple cobalt oxides, $\mathrm{CoO}$ and $\mathrm{Co}_{2} \mathrm{O}_{3}$, and $\mathrm{Co}^{3+}$ and $\mathrm{Co}^{2+}$ were detected in solution. Cyclic vol- 